\title{
Fixed Shipping Cost Allocation for Just-in-Time (JIT) Lot-Splitting
}

\author{
Joong Y. Son \\ Department of Decision Sciences, School of Business, \\ MacEwan University, Edmonton, Alberta T5J 4S2, Canada \\ Email: sonj2@macewan.ca
}

\begin{abstract}
This paper studies benefits of just-in-time (JIT) lotsplitting and multiple shipments for an order placed by the retailer in a two-stage supply chain. In a typical order placement and delivery setting between the buyer and the vendor, the treatment of the shipping cost is not clear and is contingent on negotiations between the parties involved. The outcome of such settlement often results in suboptimal practices in the supply chain. This paper investigates how the optimal and incentive aligned allocation of the fixed shipping cost from the manufacturer to the retailer can be obtained with the lotsplitting policy. Numerical results indicate that both the lotsplitting policy parameter and the fixed cost structures (e.g., fixed shipping to ordering cost ratio) command significant impact on the shipment frequency and the supply chain cost. The paper further proposes an approach to identify settings beneficial for the system.
\end{abstract}

Keywords: just-in-time, lot-splitting, shipping cost allocation, incentives

\section{INTRODUCTION}

While there is a general agreement that just-in-time (JIT) should be understood as a strategic organizational approach implemented in an integrated system (Sakakibara et al., 1997), majority of research and practices have focused on the operational aspects of JIT (Fernandes et al., 2016; Kim and Ha, 2003; Fazel, 1997). It is well-documented that the benefits of JIT system stem from the continuous improvement in quality, flexibility, and purchasing processes made possible via intimate and long-term relationships between the vendor and the buyer (Chung et al., 2015; Kim and Ha, 2003; White et al., 1999). Some of the essential factors to make this JIT buyer-vendor relationship resilient and long-lasting are mutual trust and concession (Newman, 1988) with respect to pricing, lot-sizing, and delivery frequency. The basic presumption in the buyer-vendor relationship is a win-win basis (Rosenberg and Campbell, 1985) for both sides of the business despite the fact that pricing and lot-sizing decisions have been traditionally settled through negotiations between two parties involved (Banerjee, 1986), often determined by the basic power structure. It is noted that the buyer's (i.e., the retailer's) optimal order quantity frequently results in a suboptimal production policy for the vendor (i.e., the manufacturer). This misalignment is even more apparent between two parties whose interests and goals are not compatible although they are expected to operate in a cooperative manner for the benefit of the whole system. Number of studies investigate integrated approach to resolve this issue, where joint economic lot size model is implemented to avoid misaligned ordering conditions (Banerjee, 1986) or a strategic inventory model is proposed to form an alliance between the purchaser and the vendor for profit sharing under JIT setting (Yang and Pan, 2004; Kim and Ha, 2003). Literature in joint optimization of the inventory and replenishment system which studies buyer-vendor relationship is vast from both operations management (Goyal, 1976; Monahan, 1984; Lee and Rosenblatt, 1986; Weng, 1995; Khouja et al., 2005; Porras and Dekker, 2006) and marketing perspectives (Jeuland and Shugan, 1983; Lal and Staelin, 1984; Dolan, 1987). An extensive review of integrated inventory models on the buyer-vendor coordination model is provided in Goyal and Gupta (1989).

Other studies on JIT look at the aspect of frequent usage of smaller lots in manufacturing and purchasing (Banerjee and Kim, 1995; Schonberger and Ansari, 1984) justified by minimization of the required setup costs for each lot (Chyr and Huang, 2016; Mirza and Malstrom, 1994). Pan and Liao (1989) and Kim and Ha (2003) discuss EOQ-based inventory models and develop these into JIT-based lot-splitting model to assess the impact of frequent deliveries for a single order on the total cost efficiency for the whole system as well as for each party. The impact of lot-splitting on performance measures also depends on a number of other factors including sub-lot sizes and setup times (Azzi et al., 2012; Kropp and Smunt, 1990). More recently, studies in the context of workload control (WLC) address the effectiveness of lotsplitting policies on the shop floor (Fernandes et al., 2016; Thürer et al., 2014; Cheng et al., 2013).

This paper assesses the effectiveness of an inventory replenishment system in a two-stage supply chain, where the vendor (manufacturer) and the buyer (retailer) implement a coordinated JIT-based lot-splitting system. The research is based on the premise that the JIT practice is not a stand-alone initiative, but one that requires continuous efforts to align incentives to maintain coordination between business partners, largely consistent with the concept of viewing one's supply chain partner as part of one's team and not an adversary. With this notion, this paper looks at how different cost structures can affect supply chain performance when lotsplitting policy is implemented to allow multiple deliveries for a given order. In particular, this paper proposes the optimal fixed shipping cost allocation between the vendor 
(the manufacturer) and the buyer (the retailer) with JIT lotsplitting and studies the impact of the allocation on the lotsplitting policy.

With the benefits of the JIT system widely understood in global supply chain practices, the prevalence of JIT ordering in business is now a common phenomenon over the last few decades (Chopra and Sodhi, 2014). Further, it is crucial for businesses to understand not only the benefits of JIT-based replenishment practices, but also the importance of developing the right incentive program agreeable to all parties. The main contribution of this research is that it develops an approach to find the optimal allocation of the fixed portion of the shipping cost between business partners while assessing the benefits of using JIT lot-splitting in an inventory replenishment system to identify business settings that minimize the total inventory-related costs. Insights gained from this research can further be applied to studies of other order coordination mechanisms, such as the vendormanaged inventory (VMI) system or the consignment inventory contract.

The rest of the paper is organized as follows: In the next section, research questions are presented, followed by the discussion of the inventory-based model in which the operating characteristics of the base case (locally-managed inventory system) and the JIT lot-splitting system are analysed. Numerical experiments present the results of different business scenarios of JIT lot-splitting and provide managerial insights. Conclusions and future research direction will follow in the last section.

\section{RESEARCH QUESTIONS AND FOCUS OF THE RESEARCH}

This paper investigates the benefits of JIT lot-splitting and multiple shipment deliveries for an order placed by the buyer (i.e., retailer) in a two-stage supply chain. The allocation of the fixed shipping cost and its impact will be the primary focus of this research. In operations and inventory management literature, the cost responsibility has been welldocumented with the inventory holding costs and the order placement costs being fully assumed by the buyer in majority of cases. The treatment of the fixed shipment cost associated with inventory replenishment, however, is not as clear and is often contingent on the agreements between business partners (Yao et al., 2007). Even under certain international shipping terms (e.g., FOB destination), where the supplier is expected to assume most of the transportation costs and risks, these costs are sometimes included in the final deliveredprice borne by the buyer (Leenders et al., 2006). In such cases, shipping costs are assumed to be part of the wholesale price charged to the buyer. In other cases, they may be combined with the fixed order placement costs (Rubin and Carter, 1990) or separated from the rest of the inventory- related costs to be paid to a logistics service provider (Fazel, 1997). Regardless of the cost responsibilities in order shipments, it is not uncommon to find transportation costs accounting for a significant portion (as high as 40\%) of the company's purchase expenditure (Leenders et al., 2006). More recent studies address the significance of reducing the travel costs for JIT-based on-demand pick-up and delivery via dynamic vehicle routing or dispatching systems (Lee et al., 2016; Pillac et al., 2013).

According to the International Commercial Terms or the Incoterms 2010 (International Chamber of Commerce), sellers and buyers negotiate to decide on the rules for mode of transportation, which may range from Ex Works or EXW (in which the buyer assumes most risks and costs to the destination) to Delivered Duty Paid or DDP (in which the seller is responsible for all the expenses to the destination including duties and taxes). Thus, finding the best allocation of fixed shipment costs between the seller and the buyer can have a significant impact on the cost performance and shipment practices of the entire supply chain as well as individual parties involved. This paper studies the characteristics of order placements, lot-splitting, and inventory replenishment in the system while deriving the optimal allocation of the fixed shipping cost of making shipment deliveries from the manufacturer to the retailer. The paper intends to address the following research questions:

1. How does the JIT lot-splitting policy setting impact the supply chain performance, both locally at each stakeholder and globally?

2. What is the impact of the fixed cost structures on the performance of JIT lot-splitting policy?

3. How is the optimal allocation of the fixed shipping cost derived to minimize the system-wide cost performance?

\section{JUST-IN-TIME (JIT) LOT- SPLITTING}

This paper investigates a two-stage decentralized supply chain consisting of a single vendor (manufacturer) and a single buyer (retailer). A single stock keeping unit (SKU) is supplied by the manufacturer to the retailer, with the retailer facing external demand which displays a deterministic demand pattern. In a typical inventory replenishment situation, where each business seeks to optimize its own ordering policy, the retailer will naturally benefit by implementing a locally-managed inventory (LMI) system, such as economic order quantity (EOQ) policy. In other business situations studied in this research where the retailer enters into a contract with the vendor to enable lotsplitting of each order, the retailer may consider agreeing to multiple shipment deliveries made for a single order as illustrated in Figure 1. 


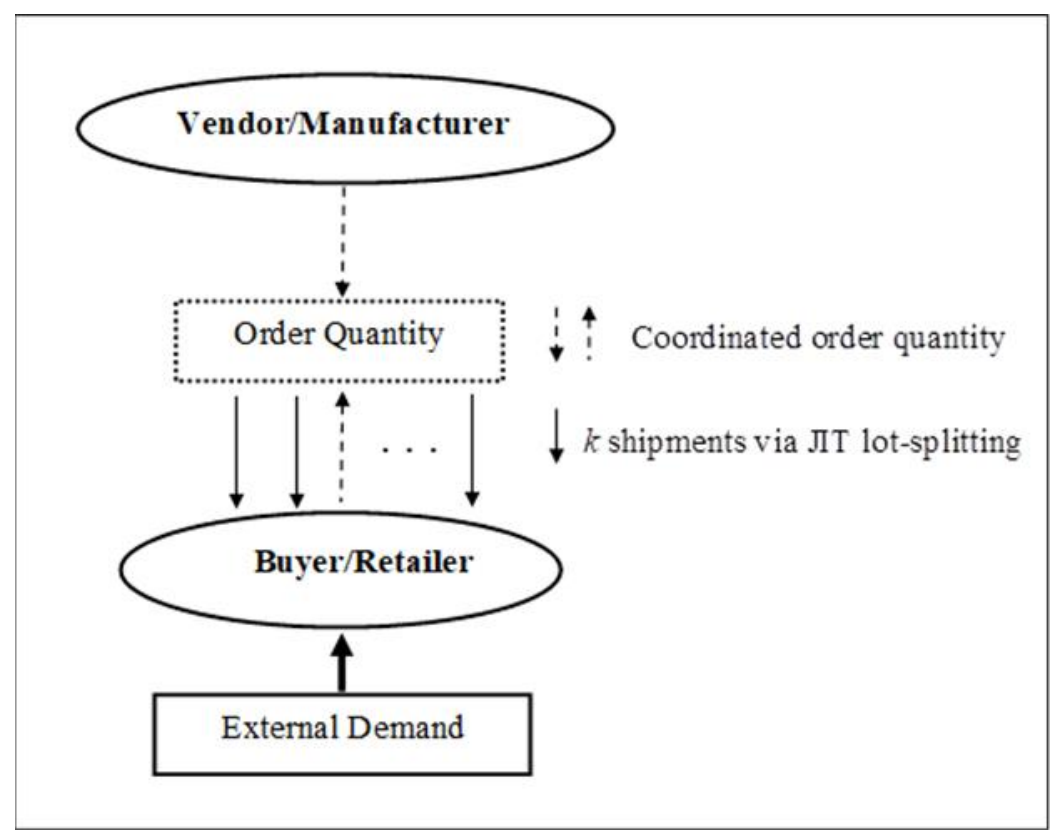

Figure 1 Supply chain configuration with JIT lot-splitting

This can be observed in blanket purchase order contracts between the vendor and the buyer, where recurring deliveries are made to the buyer over a certain period or within a predetermined quantity without purchase order issuance for every shipment made. A vendor-managed inventory (VMI) system is another example of a replenishment contract that can be implemented by adjusting, splitting, or combining lot sizes.

This section first discusses the traditional locallymanaged inventory system (e.g., an EOQ ordering) in which the retailer initiates the order and the manufacturer responds by delivering the stated quantity, followed by lot-splitting replenishment system, in which smaller quantity JIT lots (based on lot-splitting) are shipped from the manufacturer for each order. This JIT lot-splitting system naturally calls for a joint total cost approach as it is likely to be the result of a collaborative ordering agreement. A coordination plan is devised between the manufacturer and the retailer in a way that warrants consideration of the use of lot-splitting method to yield supply chain performance agreeable to all parties. In particular, a mechanism to allocate the fixed transportation cost for each shipment is proposed to reach a coordinated replenishment utilizing the JIT lot-splitting.

\subsection{Locally Managed Inventory (LMI) \\ Replenishment}

A locally-managed inventory (LMI) system is seen as a replenishment practice, in which the manufacturer responds to the retailer's order by fulfilling the order quantity as needed. In most cases, inventory and replenishment decisions are made in a decentralized manner without coordination efforts in place between the parties involved.

The paper uses the following notations for the LMI replenishment model:

$D \quad$ : Demand faced by the retailer over time (year).

$h_{B}$ : Inventory holding cost/unit/year at the buyer (retailer).

$h_{V}$ : Inventory holding cost/unit/year at the vendor (manufacturer).
$A_{B} \quad$ : Fixed ordering cost charged to the retailer for each order.

$S_{B} \quad$ : Fixed shipping cost portion charged to the retailer incurred in each shipment from the manufacturer to the retailer.

$A_{V} \quad$ : Fixed setup cost at the manufacturer.

$S_{V} \quad$ : Fixed shipping cost portion charged to the manufacturer incurred in each shipment from the manufacturer to retailer.

$S \quad$ : Total fixed shipping cost from the manufacturer to the retailer, where $S=S_{B}+S_{V}$

$Q_{E} \quad$ : Order quantity placed by the retailer.

$T C_{B}^{E}$ : Total inventory and replenishment cost over time (year) at the retailer.

$T C_{V}^{E}$ : Total inventory and replenishment cost over time (year) at the manufacturer.

When the retailer faces a deterministic market demand, the natural ordering practice in an LMI system constitutes EOQ replenishment. An order quantity of $Q_{E}$ is placed with the manufacturer by the retailer as shown in (1).

$$
Q_{E}=\sqrt{\frac{2 \cdot D \cdot\left(A_{B}+S_{B}\right)}{h_{B}}}
$$

Total inventory-related costs for the retailer and the manufacturer when the LMI system is implemented with an EOQ ordering are expressed in (2) and (3) respectively:

$$
\begin{aligned}
& T C_{B}^{E}=\frac{Q_{E}}{2} h_{B}+\frac{D}{Q_{E}}\left(A_{B}+S_{B}\right) \\
& T C_{V}^{E}=\bar{I}_{V} h_{V}+\frac{D}{Q_{V}} A_{V}+\frac{D}{Q_{E}} S_{V}
\end{aligned}
$$

where $Q_{V}$ and $\bar{I}_{V}$ represent the size of the production batch and the average inventory level at the manufacturer. 


\subsection{JIT-Based Lot-Splitting}

JIT-based lot-splitting model has been studied in production and inventory management literature (Schniederjans and Cao, 2001; Fazel, 1997; Sakakibara et al., 1997; Pan and Liao, 1989) to show that maximum benefits are achievable when JIT system operates as an integrated system. The lot-splitting approach presented in this paper is based on the method proposed by Pan and Liao (1989), where order quantities are determined for different number of order (or lot) splits. The total batch size for each setup, denoted as $Q_{k}^{J}$, will be split into $k$ equal size shipments to be made from the manufacturer to the buyer. Thus, $Q_{k}^{J} / k$ indicates the size of each of the $k$ shipments. For such a JIT-based lot-splitting ordering, optimal order lot size $Q_{k}^{J}(B)$ and the total inventory and replenishment $\operatorname{cost}\left(T C_{B}^{J}\right)$ for the retailer can be written as in (4) and (5).

$$
\begin{aligned}
& Q_{k}^{J}(B)=\sqrt{\frac{2 k D\left(A_{B}+k S_{B}\right)}{h_{B}}} \\
& T C_{B}^{J}\left(\frac{Q_{k}^{J}(B)}{k}\right)=\sqrt{\frac{2 h_{B}\left(A_{B}+k S_{B}\right) D}{k}}
\end{aligned}
$$

The idea of order splitting studied here can be viewed as setting up a blanket purchase order between supply chain partners, the manufacturer and the retailer, in which for a given order placed by the retailer, $k$ equal shipments are being released by the manufacturer to the retailer as recurring purchases. Now the total inventory-related cost at the manufacturer $\left(T C_{V}^{J}\right)$ is derived as:

$$
T C_{V}^{J}\left(\frac{Q_{k}^{J}}{k}\right)=\frac{D}{Q_{k}^{J}} A_{V}+\frac{D}{Q_{k}^{J}} k S_{V}+\frac{1}{2} Q_{k}^{J}\left(\frac{k-1}{k}\right) h_{V}
$$

The optimal production lot size for a given $k$ from the manufacturer's perspective, $Q_{k}^{J}(V)$, is determined by taking the first derivative of the total cost function in (6) with respect to $Q_{k}^{J}$, and solving for $Q_{k}^{J}$ with the result shown in (7)

$$
Q_{k}^{J}(V)=\sqrt{\frac{2 k D\left(A_{V}+k S_{V}\right)}{(k-1) h_{V}}}
$$

The relationships in (6) and (7) are solely based on the manufacturer's inventory-related costs irrespective of the retailer's cost or ordering situation. Theoretically, the manufacturer finds the most profitable (or cost-minimizing) batch size when $k=1$ and makes a single shipment per order out to the retailer all at once as much as the capacity allows, which may neither be an ideal nor a reality-based practice for the whole system. For other cases with actual lot-splitting (i.e., $k=2,3$, 4, etc.), the manufacturer's inventory-related cost can be rewritten from the results in (6) and (7) as:

$T C_{V}^{J}\left(\frac{Q_{k}^{J}(V)}{k}\right)=\sqrt{\frac{2 h_{V}\left(A_{V}+k S_{V}\right) D(k-1)}{k}}$

With the results obtained previously in (5) and (6) for the retailer and the manufacturer respectively, the optimal order quantity from the system's perspective $Q_{k}^{J}(S)$ and the resulting total system cost $T C_{S}^{J}\left(\frac{Q_{k}^{J}(S)}{k}\right)$ are expressed as in (9) and (10) below:

$Q_{k}^{J}(S)=\sqrt{\frac{2 k D\left[A_{B}+A_{V}+k\left(S_{B}+S_{V}\right)\right]}{h_{B}+(k-1) h_{V}}}$

$T C_{S}^{J}\left(\frac{Q_{k}^{J}(S)}{k}\right)=$

$\sqrt{\frac{2 D\left[h_{B}+(k-1) h_{V}\right] \cdot\left[A_{B}+A_{V}+k\left(S_{B}+S_{V}\right)\right]}{k}}$

The inventory path for the typical lot-splitting implementation (e.g., ordering $Q_{3}^{J}(S)$ with $k=3$ ) can be depicted in comparison to the EOQ ordering $\left(Q_{E}\right)$ as displayed in Figure 2.

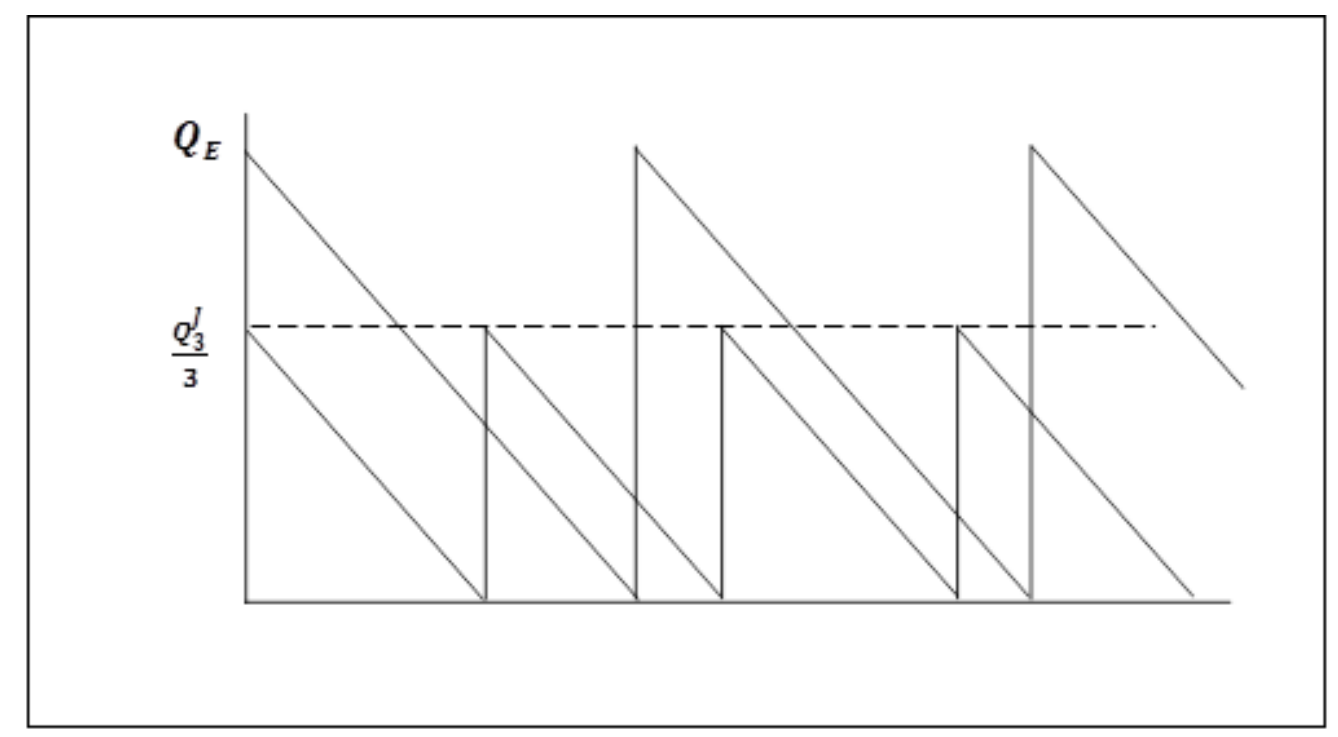

Figure 2 JIT lot-splitting vs. EOQ ordering system 


\subsection{Incentive-aligned Approach for JIT Lot- Splitting \\ Results of the analysis of the proposed JIT lot-splitting} point to the fact that the optimal order quantity obtained for the manufacturer, $Q_{k}^{J}(V)$, and the retailer, $Q_{k}^{J}(B)$, are different for each value of $k$. Further, neither of the two quantities align with the optimal order quantity for a given value of $k$ from the system's perspective revealed in (9) which results in the minimum system-wide inventory-related cost. Based on the notion that JIT-based lot-splitting creates an environment more favourable to the retailer than the manufacturer with multiple deliveries per order and low onhand inventory at the retailer level, main emphasis in developing a mutually aggregable lot-splitting replenishment will be focused on deriving an incentive-compatible allocation of the fixed shipping cost between the manufacturer and the retailer. Each stakeholder naturally prefers having most, if not all, of the fixed transportation cost of each shipment (total of $k$ shipments for each order) from the manufacturer to the retailer to be charged to the other party. This is more apparent for situations in which the fixed shipping cost accounts for a significant portion of the total inventory and replenishment expenses.

From the retailer's perspective, receiving multiple shipments through the JIT lot-splitting may constitute a dominant policy over its LMI-based approach (i.e., an EOQ ordering) for all values of $k(>1)$ as long as the fixed shipping cost allocation with the manufacturer is rationalized both globally and locally. The same logic, however, does not necessarily apply to the manufacturer as multiple shipments to the retailer for each order are likely to result in a significantly higher cost for the manufacturer when compared to the EOQ ordering. Even with a favourable fixed shipping cost allocation for the manufacturer (i.e., with a greater portion of the fixed cost charged to the retailer), an increase in the inventory holding at the manufacturer as a result of the lot-splitting can easily lead to higher inventoryrelated costs for the manufacturer compared to the LMIbased policy. Therefore, the ideal allocation of the fixed shipping cost between the manufacturer and the retailer for the lot-splitting policy should be determined in such a way that each party identifies the best allocation that results in the alignment of optimal order quantities for both parties for a given value of $k$. The optimal fixed shipping cost allocated to the buyer for a given $k$, thus, is obtained by equating (4) and (7) as

$S_{B}=\frac{h_{B}\left(A_{V}+k S\right)-(k-1) A_{B} h_{V}}{k\left[(k-1) h_{V}+h_{B}\right]}$

The optimal allocation shown in (11) is also consistent with the system cost-minimizing order quantity, $Q_{k}^{J}(S)$, obtained in (9). It should be noted, however, that identifying the optimal allocation of the fixed shipping cost for a given $k$ does not guarantee an equitable result for both parties involved as the impact of shipment frequency $(k)$ should be quite the opposite for each party. Thus, regardless of this allocation, additional cost sharing mechanism is warranted between the two parties in such a way that the disparity in the benefits of the lot-splitting practice can be resolved.
The numerical experiments that follow address each research question in detail. Discussions of research questions and managerial implications will be centred on the impact of the lot-splitting policy (e.g., the effects of the shipment frequency, $k$, for each order) on supply chain costs as well as on the optimal shipping cost allocation. Results from the numerical experiments should provide insights on the operating characteristics of the JIT lot-splitting while identifying settings for which implementing lot-splitting practice would be beneficial for the system and individual stakeholders.

\section{NUMERICAL RESULTS AND MANAGERIAL INSIGHTS}

\subsection{Settings for Numerical Experiments}

Parameters for the numerical experiments are selected to reflect the deterministic nature of the market demand with which the JIT lot-splitting is implemented. The numerical experiments investigate the impact of the policy parameter (the delivery frequency, $k$, for each order,) as well as structural parameters (e.g., cost ratios) on supply chain performance measures.

Table 1 Parameters and assumptions of numerical experiments

\begin{tabular}{|c|}
\hline Cost parameters \\
\hline Holding cost rate $(k)=20 \%$ per year \\
\hline Whole price $=\$ 100 /$ unit \\
\hline Manufacturing cost $=\$ 50 /$ unit \\
\hline Vendor's fixed setup cost $\left(A_{V}\right)=\$ 500 /$ setup \\
\hline Vendor's fixed shipping cost $\left(S_{V}\right)$ : To be determined \\
\hline Retailer's fixed ordering cost $\left(A_{B}\right)=\$ 500 /$ order \\
\hline Retailer's fixed shipping cost $\left(S_{B}\right)$ : To be determined \\
\hline $\begin{array}{l}\text { Fixed shipping cost to be allocated between the manufacturer } \\
\text { and the retailer } \\
\left(S=S_{B}+S_{V}\right)\end{array}$ \\
\hline Cost structure $\left(S / A_{B}\right)=0.1,0.5,1.0,2.0$ \\
\hline Cost structure $\left(S_{B} / S\right)=0.0,0.25,0.50,0.75,1.0$ \\
\hline Design \& policy parameters \\
\hline Total demand $(D)=10,000$ units/year \\
\hline Lot-splitting parameter $(k)=2,3,4,5,6, E O Q$ \\
\hline Assumptions \\
\hline Demand: Steady and deterministic \\
\hline Supply chain structure: Single manufacturer - single retailer \\
\hline Base case: LMI assumes the EOQ ordering by the retailer \\
\hline $\begin{array}{l}\text { Lot-splitting policy: New delivery arrives at the retailer just as } \\
\text { the previous delivery quantity is depleted. }\end{array}$ \\
\hline
\end{tabular}

In particular, different sets of purchasing agreement scenarios are studied to evaluate the impact of lot-splitting and multiple deliveries of the smaller equal-size shipments. The base case used for the numerical experiments is the LMIbased EOQ ordering system. It is also assumed that, for the 
JIT lot-splitting policy, $k$ deliveries are arranged for each order in such a way that the new shipment of size, $Q_{k}^{J} / k$, arrives at the retailer just as the previous delivery quantity is depleted. Comparisons are conducted for business situations that encompass various replenishment scenarios of lotsplitting policy and cost-structures: six different scenarios of lot-splitting parameters $(k=2,3,4,5,6$, and EOQ ordering) are combined with four shipping cost ratios at the retailer $\left(S_{B} / S=0.1,0.5,1.0\right.$, and 2.0$)$ and five shipping-to-ordering cost ratios for the retailer $\left(S / A_{B}=0.0,0.25,0.50,0.75\right.$. and 1.0) for total combination of $120(=6 \times 4 \times 5)$ distinct purchasing and replenishment scenarios. Parameters and assumptions for the numerical experiments are summarized in Table 1

\subsection{Impact of Lot-Splitting Shipments for Each Order)}

(Number of

As discussed in the previous section on the analytical modeling of the system, the optimal order quantity is defined for each stakeholder as well as for the system under the JIT lot-splitting policy. It is clear from the result in equation (4) that the order quantity that minimizes the retailer's inventoryrelated costs increases in the lot-splitting parameter $(k)$, but the optimal shipment quantity for the retailer for each order, $Q_{k}^{J}(B) / k$, decreases in $k$ as shown in Figure 3. That is, unless fixed costs of replenishment (both the ordering and the shipping costs) are small and negligible, the optimal order quantity should be large enough to rationalize multiple deliveries $(k)$ for each order. For a given value of $k$, it is also observed that a lower ratio of $S_{B} / S$ results in a smaller optimal shipment quantity, which indicates a lower fixed transportation cost allotted to the retailer justifies a small delivery lot size for each shipment from the retailer's perspective.

A similar pattern is revealed with the optimal order and the shipment quantity from the system's perspective when JIT lot-splitting is used. That is, the order quantity displays a monotonically increasing pattern in $k$, whereas, the shipment quantity shows a decreasing pattern in $k$ as in Figure $\mathbf{4}$ and Figure 5. It is noted that the fixed shipping cost allocation between the manufacturer $\left(S_{V}\right)$ and the retailer $\left(S_{B}\right)$ has no bearing on the shipment quantity for the system or on the total system costs, as the system performance measures are impacted only by the sum of the two fixed shipping cost components (i.e., $S$ ), and not by the individual allocation of $S$ between the two parties. Fixed shipping-to-ordering cost ratio (i.e., $S / A_{B}$ ), however, is pertinent to how the optimal shipment quantity is determined. Figure 4 reveals that for any given ratios of the fixed shipping-to-ordering cost, the optimal order quantity increases in the shipment frequency, $k$, implying that frequent shipments in JIT-based lot-splitting practice should be justified by having a sufficiently large order quantity that balances the shipping $(S)$ and the ordering costs $\left(A_{B}\right)$.

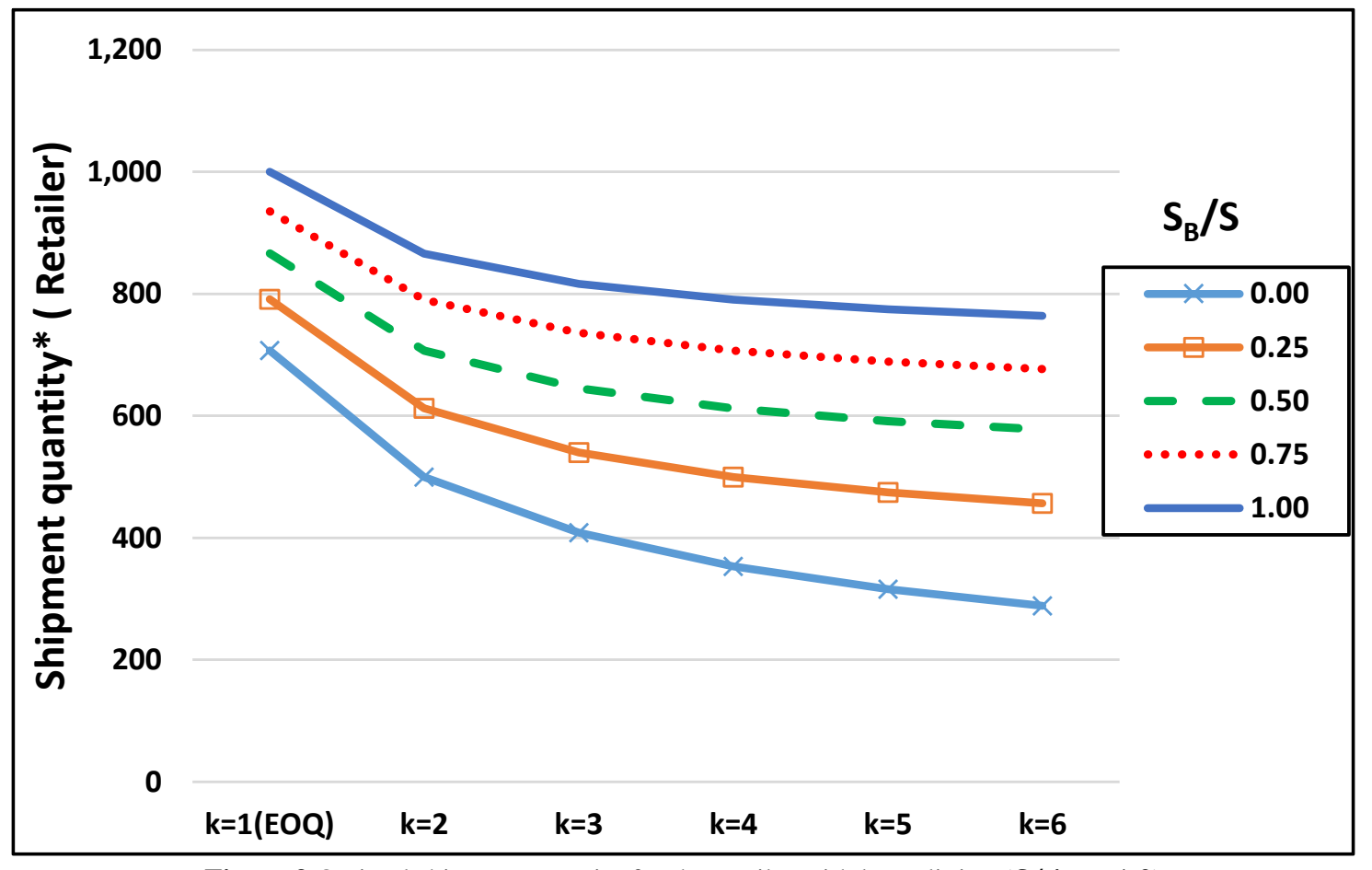

Figure 3 Optimal shipment quantity for the retailer with lot-splitting $\left(S / A_{B}=1.0\right)$ 


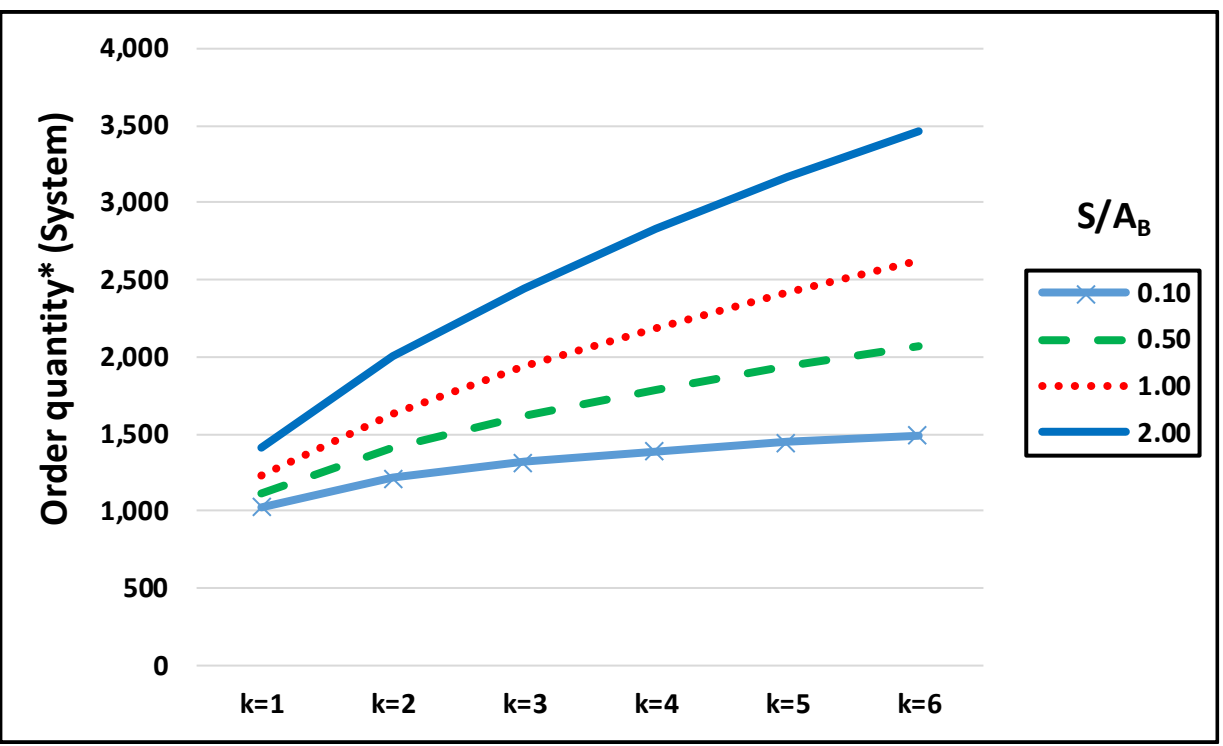

Figure 4 Optimal order quantity for the system with lot-splitting

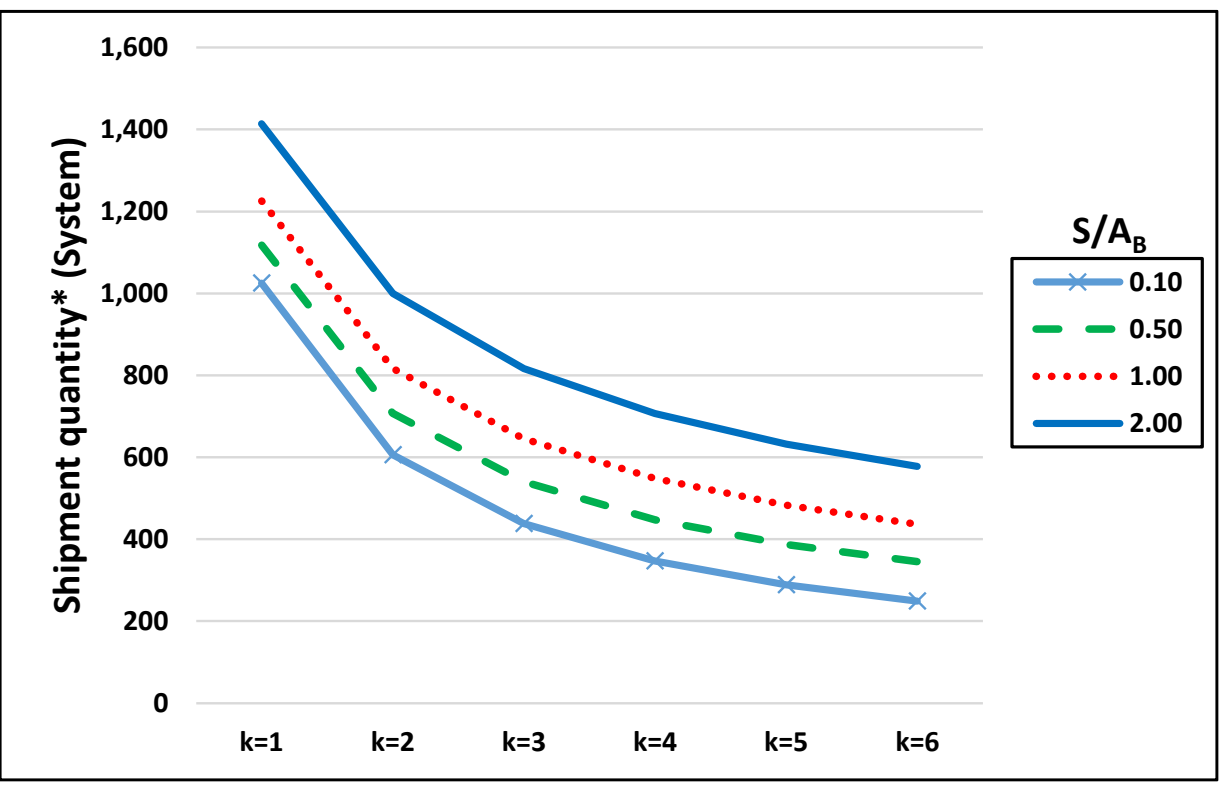

Figure 5 Optimal shipment quantity for the system with lot-splitting

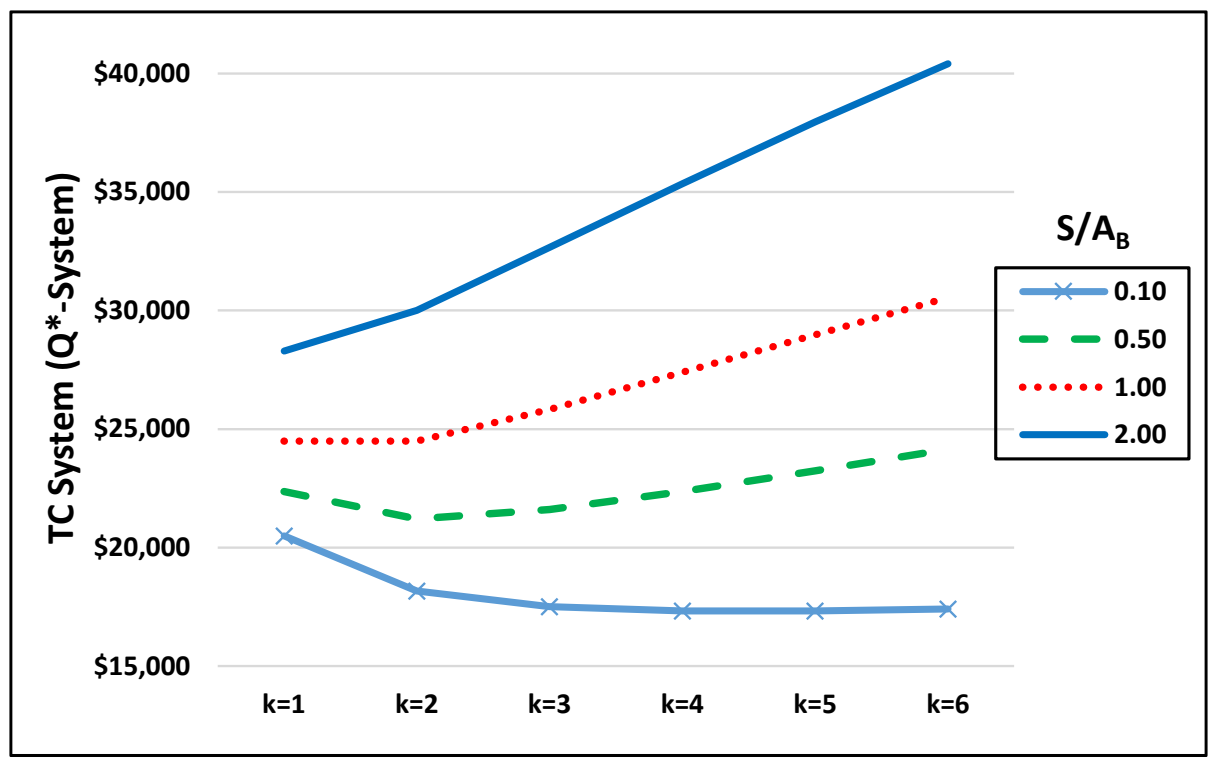

Figure 6 Total inventory cost for the system with optimal shipment quantity (system) 
In a result that is directly related to the optimal order quantity discussed above, Figure 5 illustrates that for a given value of $k$, the lower the $S / A_{B}$, the smaller the optimal shipment quantity for the system, which again warrants more frequent deliveries for each order (i.e., a larger $k$ ).

Further, for optimal shipment quantities for the system obtained in Figure 5 for each combination of $k$ and $S / A_{B}$, inventory-related costs for the system are displayed in Figure 6, revealing that the delivery frequency determined by lotsplitting shows a consistent pattern for any given values of $S / A_{B}$, ranging from 0.10 to 2.0 . For all values of $k$, inventory cost for the system shows a convex pattern. In particular, for a lower fixed cost ratio of $S / A_{B}$, say 0.10 , there is greater incentive for having more deliveries $(k)$ made for a given order, whereas for a larger fixed cost ratio, $S / A_{B}$, of 2.0, lotsplitting practice $(k \geq 2)$ always results in higher inventoryrelated costs. Smaller lot sizes based on JIT lot-splitting are rationalized for the system under business scenarios where the fixed shipping cost can be significantly reduced. In practice, third-party logistics (3PL) services are often helpful in reducing the fixed shipping costs and putting lot-splitting applications to work (Tezuka, 2011).

\subsection{Impact of the Fixed Cost Structures on JIT Lot-Splitting}

It is apparent that the system cost performance of the JIT lot-splitting depends on cost structures between business partners. In addition to $S / A_{B}$, the fixed shipping cost allocation between the manufacturer and the retailer is shown to command a significant impact on the overall system cost. As previously shown in equation (11), the optimal allocation, $S_{B} / S^{*}$, is determined for each lot-splitting parameter, $k$. Figure 7 shows a gradually decreasing pattern of the optimal allocation, $S_{B} / S^{*}$, in $k$ when the fixed shipping-to-ordering cost ratio is in parity (i.e., $S / A_{B}=1.0$ ) reconfirming that a larger value of shipment frequency $(k)$ should only be justified by a relatively low value of the fixed shipping cost proportion allocated to the retailer for the sake of minimizing the total system cost.

Thus, with frequent shipments $(k)$ made for each order, it is optimal for the system to have much greater proportion of the fixed shipping cost allocated to the manufacturer creating a setting favourable to the retailer in terms of lowering both the shipping and the inventory holding cost. This impact is even more pronounced as the unit inventory holding cost is generally greater at the retailer than at the manufacturer, making it profitable from the system's perspective to set a small enough value of $S_{B} / S$ as it provides the incentive for frequent deliveries for each order and saves on the holding costs.

It is also worth assessing general impact of the fixed shipping cost, $S$, on the total system costs. For cases with a small ratio of $S / A_{B}$, (e.g., $S / A_{B}=0.10$ ), the total system cost function with the optimal $S_{B} / S^{*}$ applied for a given $k$ as per equation (11) displays a clear convexity in $k$ as shown in Figure 8. Multiple deliveries for each order lead to cost minimization around $k=4$ or 5 , at which point JIT lot-splitting fully utilizes the advantage of cheaper shipping cost $(S)$. More frequent shipments (i.e., $k>5$ ) make JIT lot-splitting practice more costly for the system due to the increase in the total shipping expenses. On the contrary, for a significantly higher ratio of $S / A_{B}$, (e.g., $\left.S / A_{B}=2.0\right)$, implementing a JIT lot-splitting practice for the inventory replenishment may not even be a viable option as the total system costs monotonically increase in the shipment frequency, $k$, as previously observed in Figure 6.

The analysis of the fixed shipping cost reveals that the optimal allocation $S_{B} / S^{*}$ is the point at which the optimal order quantities for the retailer and the manufacturer align, and total system cost is minimized. Thus, it constitutes the point that equates all three optimal ordering quantities, $Q_{k}^{J *}(S), Q_{k}^{J *}(B)$, and $Q_{k}^{J *}(V)$, as confirmed in Figure 9.

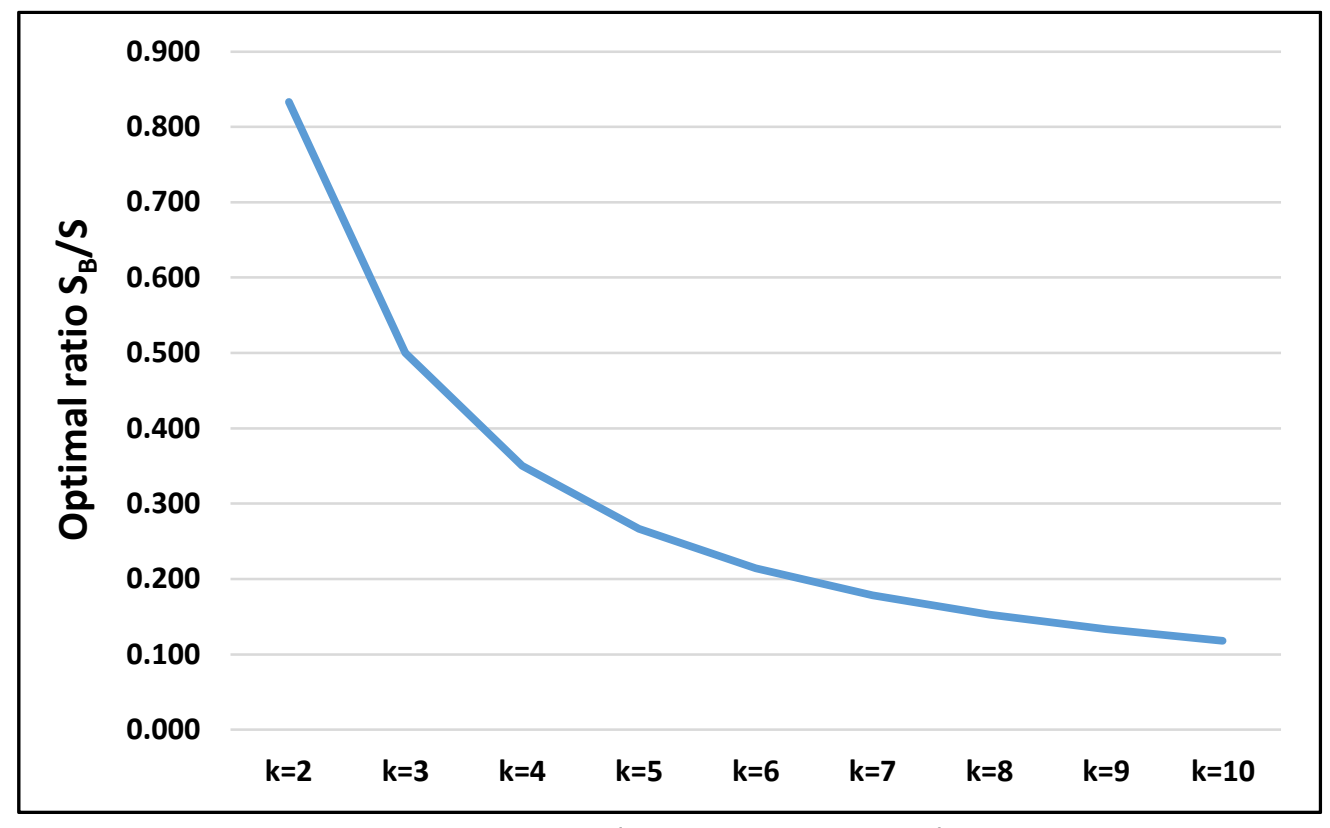

Figure 7 Optimal ratio, $S_{B} / S$, for each value of $k\left(S / A_{B}=1.0\right)$ 


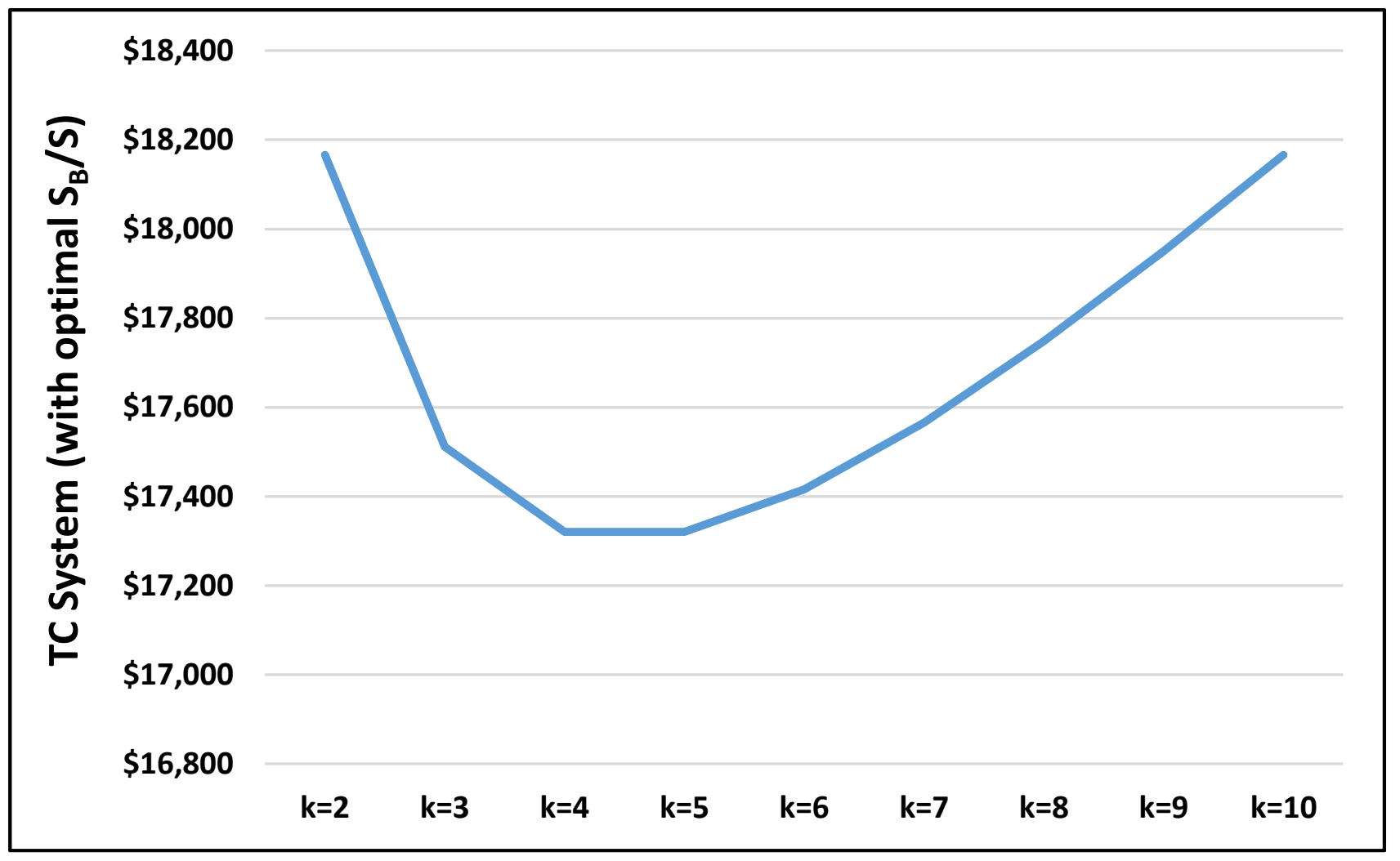

Figure 8 Total system costs with optimal ratio, $S_{B} / S$, for each value of $k\left(S / A_{B}=0.10\right)$

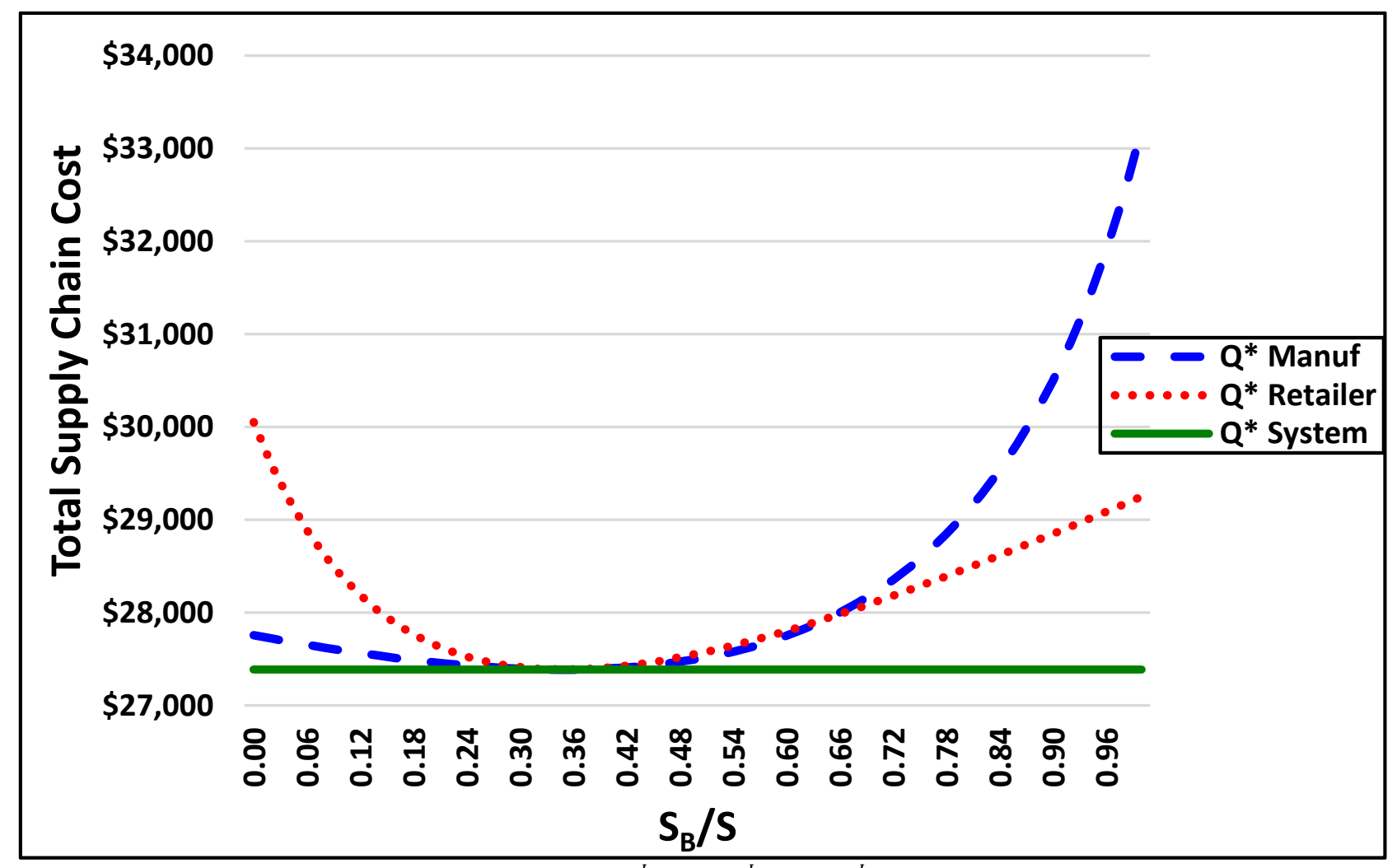

Figure 9 Total cost comparison: $Q_{k}^{J}(S)$ vs. $Q_{k}^{J}(B)$ vs. $Q_{k}^{J}(V)\left(S / A_{B}=1.0 ; k=4\right)$ 
For $S / A_{B}=1.0$ and $k=4$, the total system costminimizing quantities for the manufacturer, the retailer, and the system coincide at the optimal allocation point, $S_{B} / S=0.35$ for the equal order quantity of $Q_{k}^{J *}(S)=Q_{k}^{J *}(B)=$ $Q_{k}^{J *}(V)=2,191$, and the equal shipping quantity of $Q_{k}^{J *}(S) /$ $k=548$. The total system cost stays constant in $S_{B} / S$ for a given value of $k$ as displayed in Figure 9 and will only vary with any changes to $S$ or $S / A_{B}$ as the allocation of the fixed shipping cost between the manufacturer and the retailer does not impact the total system cost as previously discussed. All of the aforementioned discussions on the impact of lotsplitting and the fixed cost structures are included in the summary of relationship in Table 2, which displays how the optimal order quantity, the optimal shipment quantity, inventory-related cost, and the fixed shipping cost allocation vary as lot-splitting practice progresses (i.e., as $k$ increases) in the inventory replenishment for a given cost structure, $S / A_{B}$. It is worth noting that for cases in which the fixed shipping cost $(S)$ is sufficiently low, the effectiveness of JIT lot-splitting is most evident. Further, in order to rationalize a higher shipment frequency $(k)$, numerical results indicate it is optimal for the system to have smaller (larger) proportion of fixed shipping cost allotted to the retailer (manufacturer) as summarized in Table 2.

Finally, the paper examines the possibility of cost sharing within the system using cost comparisons of each party as well as the whole supply chain. That is, local costs are being compared against the supply chain cost using EOQ, $Q_{k}^{J *}(B), Q_{k}^{J *}(V)$, and $Q_{k}^{J *}(S)$. Numerical results are illustrated in Table 3 for replenishment scenario with $k=4$ and $S / A_{B}=0.5$, for which the optimal allocation of $S_{B} / S^{*}=0.30$ is obtained. According to Table 3, applying the JIT lot-splitting leads to a lower system-wide cost than the EOQ-based system cost $(\$ 22,360$ vs. $\$ 24,068)$ for the parameters and the optimal allocation used. It is evident that the major part of the system cost improvement is due to the improvement in the retailer cost (from $\$ 15,166$ to $\$ 8,944$ ) by implementing the JIT lot-splitting as opposed to the traditional LMI-based ordering. Meanwhile, the manufacturer experiences a significant cost increase (from $\$ 8,902$ to $\$ 13,416$ ) as a result of the JIT lot-splitting implementation due to multiple deliveries to be made for each order and the larger portion of the fixed shipping cost allotted to the manufacturer (70\%). JIT lot-splitting clearly favours the retailer in terms of inventory cost savings. Thus, with all the system cost improvement possible via JIT lotsplitting as observed throughout numerical experiments, it is crucial that additional cost sharing mechanism should be in place between the manufacturer and the retailer to resolve any disparity in cost savings in such a way that JIT lotsplitting can effectively function as an incentive aligned coordination between the two parties involved.

Table 2 Impact of lot-splitting (increase in $k$ )

\begin{tabular}{|l|l|c|c|c|}
\hline \multicolumn{2}{|c|}{} & Retailer & Manufacturer & System \\
\hline \multirow{4}{*}{ An increase in $k$} & Optimal order quantity & & \\
\cline { 2 - 5 } & $\begin{array}{l}\text { Optimal shipment } \\
\text { quantity }\end{array}$ & $\begin{array}{l}\text { Inventory-related cost } \\
\left.\text { (Small } S / A_{B}\right)\end{array}$ & $\searrow$ & \\
\cline { 2 - 5 } & $\begin{array}{l}\text { Inventory-related cost } \\
\left(\text { Large } S / A_{B}\right)\end{array}$ & $\searrow$ & \\
\hline & $\begin{array}{l}\text { Optimal allocation ratio, } \\
S_{B} / S\end{array}$ & N/A & N/A & \\
\hline
\end{tabular}


Table 3 Cost comparisons $\left(k=4 ; S / A_{B}=0.5 ; S_{B} / S\right.$ (optimal $\left.)=0.3\right)$

\begin{tabular}{|l|r|r|r|r|r|r|}
\hline \multicolumn{2}{|l|}{ Shipment quantity } & & Optimal & & \\
\hline S(B)/S Shp & 0,00 & 0,25 & $0.30 *$ & 0,50 & 0,75 & 1,00 \\
\hline LMI & 707 & 750 & 758 & 791 & 829 & 866 \\
\hline Q-J (B) & 354 & 433 & 447 & 500 & 559 & 612 \\
\hline Q-J (V) & 500 & 457 & 447 & 408 & 354 & 289 \\
\hline Q-J (S) & 447 & 447 & 447 & 447 & 447 & 447 \\
\hline
\end{tabular}

\begin{tabular}{|c|r|r|r|r|r|r|}
\hline \multicolumn{3}{|l|}{ Total cost at the retailer } & \multicolumn{1}{l|}{ Optimal } & & \\
\hline S(B)/S Shp & 0,00 & 0,25 & $0.30 *$ & 0,50 & 0,75 & 1,00 \\
\hline TC(B) LMI & $\$ 14.142$ & $\$ 15.000$ & $\$ 15.166$ & $\$ 15.811$ & $\$ 16.583$ & $\$ 17.321$ \\
\hline TC(B) Q-J(B) & $\$ 7.071$ & $\$ 8.660$ & $\$ 8.944$ & $\$ 10.000$ & $\$ 11.180$ & $\$ 12.247$ \\
\hline TC(B) Q-J(V) & $\$ 7.500$ & $\$ 8.672$ & $\$ 8.944$ & $\$ 10.206$ & $\$ 12.374$ & $\$ 15.877$ \\
\hline TC(B) Q-J(S) & $\$ 7.267$ & $\$ 8.665$ & $\$ 8.944$ & $\$ 10.062$ & $\$ 12.460$ & $\$ 12.857$ \\
\hline
\end{tabular}

\begin{tabular}{|c|r|r|r|r|r|r|}
\hline \multicolumn{3}{|l|}{ Total cost at the manufacturer } & \multicolumn{1}{l|}{ Optimal } & & \\
\hline S(B)/S Shp & 0,00 & 0,25 & $0.30 *$ & 0,50 & 0,75 & 1,00 \\
\hline TC(V) LMI & $\$ 10.607$ & $\$ 9.167$ & $\$ 8.902$ & $\$ 7.906$ & $\$ 6.784$ & $\$ 5.774$ \\
\hline TC(V) Q-J(B) & $\$ 15.910$ & $\$ 13.712$ & $\$ 13.416$ & $\$ 12.500$ & $\$ 11.739$ & $\$ 11.227$ \\
\hline TC(V) Q-J(V) & $\$ 15.000$ & $\$ 13.693$ & $\$ 13.416$ & $\$ 12.247$ & $\$ 10.607$ & $\$ 8.660$ \\
\hline TC(V) Q-J(S) & $\$ 15.093$ & $\$ 13.696$ & $\$ 13.416$ & $\$ 12.298$ & $\$ 10.901$ & $\$ 9.503$ \\
\hline
\end{tabular}

\begin{tabular}{|c|r|r|r|r|r|r|}
\hline \multicolumn{3}{|l|}{ Total cost for the system } & Optimal & & \\
\hline S(B)/S Shp & 0,00 & 0,25 & $0.30 *$ & 0,50 & 0,75 & 1,00 \\
\hline TC(S) LMI & $\$ 24.749$ & $\$ 24.167$ & $\$ 24.068$ & $\$ 23.717$ & $\$ 23.367$ & $\$ 23.095$ \\
\hline TC(S) Q-J(B) & $\$ 22.981$ & $\$ 22.372$ & $\$ 22.360$ & $\$ 22.500$ & $\$ 22.919$ & $\$ 23.474$ \\
\hline TC(S) Q-J(V) & $\$ 22.500$ & $\$ 22.365$ & $\$ 22.360$ & $\$ 22.453$ & $\$ 22.981$ & $\$ 24.537$ \\
\cline { 1 - 1 } TC(S) Q-J(S) & $\$ 22.360$ & $\$ 22.361$ & $\$ 22.360$ & $\$ 22.360$ & $\$ 23.361$ & $\$ 22.360$ \\
\hline
\end{tabular}

\section{CONCLUDING REMARKS AND FUTURE RESEARCH}

There has been a significant number of studies comparing JIT-based lot-splitting and EOQ ordering systems (Fernandes et al., 2016; Chang and Chiu, 2005; Fazel, 1997). Some of the earlier studies (Johnson and Stice, 1993; Jones, 1991) point out that traditional inventory management systems, such as the EOQ ordering practice, tend to underestimate relevant costs associated with carrying inventory resulting in the overestimation of the order quantity in comparison to JIT lot-splitting approach. It should be noted, however, with the advancement of the information technology, availability of affordable logistics services, and shrinkage of product life cycles, JIT lot-splitting is clearly an attractive option as an inventory replenishment practice.

This research provides insights on the benefits of JIT lot-splitting system when the optimal allocation of the fixed transportation cost is obtained. The paper shows that the lotsplitting decision $(k)$ determines the optimal allocation of the fixed shipping cost, which leads to the minimum total system-wide inventory cost. In order to reach a genuine supply chain coordination by means of JIT lot-splitting proposed in this research, development of an additional incentive mechanism is needed in order to have cost sharing plan embedded in the replenishment program.

This paper contributes to the existing research stream on JIT lot-splitting by focusing on the impact of fixed cost structures within the two-stage supply chain. Developing a JIT lot-splitting model in a multi-retailer system should overcome certain limitations posed by this research and provide the right direction for future extension to this study. That is, a multi-retailer system can provide insights on ideal supply chain design when lot-splitting is used between a single manufacturer and multiple retailers who may be heterogeneous in demand pattern and market shares. Among other agendas that can be considered a viable extension of the research on JIT lot-splitting are studies of coordinated replenishment contracts such as the VMI system, the consignment inventory contract, or the quantity flexibility (QF) contract where the inventory replenishment is the primary decision made by the vendor.

\section{REFERENCES}

Azzi, A., Maurizio, F., and Persona, A. (2012). Lot-splitting scheduling procedure for makespan reduction and machine capacity increase in a hybrid flow shop with batch production. 
The International Journal of Advanced Manufacturing Technology, 59(5), pp. 775-786.

Banerjee, A. (1986). A joint economic-lot-size model for purchase and vendor. Decision Sciences, 17(3), pp. 292-311.

Banerjee, A., and Kim, S.L. (1995). An integrated JIT inventory model. International Journal of Operations and Production Management, 15(9), pp. 237-244.

Chang, J. H., and Chiu, H.N. (2005). A comprehensive review of lot streaming. International Journal of Production Research, 43(8), pp. 1515-1536.

Cheng, M., Mukherjee, N.J., and Sarin, S.C. (2013). A review of lot streaming. International Journal of Production Research, 51(23-24), pp. 7023-7046.

Chopra, S., and Sodhi, M.S. (2014). Reducing the risk of supply chain disruptions. Sloan Management Review, 55(3), pp. 7380 .

Chung, K., Lin, T., and Srivastava, H. (2015). An alternative solution technique of the JIT lot-splitting model for supply chain management. Applied Mathematics and Information Systems, 9(2), pp. 583-392.

Chyr, F.C., and Huang, S.Y. (2016). The maximum setup time and setup cost of achieving Just-in-time system. Journal of Business Theory and Practice, 4(1), pp. 75-84.

Dolan, R. J. (1987). Quantity discounts: managerial issues and research opportunities. Marketing Science, 6(1), pp. 1-27.

Fazel, F. (1997). A comparative analysis of inventory costs of JIT and EOQ purchasing. International Journal of Physical Distribution \& Logistics Management, 27(8), pp. 496-504.

Fernandes, N.O., Land, M.J., and Carmo-Silva, S. (2016). Aligning workload control theory and practice: Lot-splitting and operation overlapping issues. International Journal of Production Research, 54(10), pp. 2965-2975.

Goyal, S.K. (1976). An integrated inventory model for a single supplier-single customer problem. International Journal of Production Research, 15 (1), pp. 107-111.

Goyal, S.K., and Gupta, Y. (1989). Integrated inventory models: The buyer-vendor coordination. European Journal of Operational Research, 41(3), pp. 261-269.

Jeuland, A. P., and Shugan, S.M. (1983). Managing channel profits. Marketing Science, 2(3), pp. 239-272.

Johnson, G.H., and Stice, J.D. (1993). Not quite just-in-time inventories. The National Public Accountant, 38(3), pp. 26-29.

Jones, D.J. (1991). JIT and EOQ model: Odd couple no more. Management Accounting, 72(8), pp. 54-57.

Khouja, M., Park, S., and Saydam, C. (2005). Joint replenishment problem under continuous unit change. International Journal of Production Research, 43(2), pp. 311-326

Kim, S.L., and Ha, D. (2003). A JIT lot-splitting model for supply chain management: Enhancing buyer-supplier linkage. International Journal of Production Economics, 86(1), pp. 110.

Kropp, D. H., and Smunt, T. L. (1990). Optimal and heuristic models for lot-splitting in a flow shop. Decision Sciences, 21(4), pp. 691-709.

Lal, R., and Staelin, R. (1984). An approach for developing an optimal discount pricing policy. Management Science, 30(12), pp. 1524-1539.

Lee, S., Kang, Y., and Prabhu, V.V. (2016). Smart logistics: Distributed control of green crowdsourced parcel services. International Journal of Production Research, 54(23), pp. 6956-6968.
Lee, H., and Rosenblatt, M.J. (1986). A generalized quantity discount pricing model to increase supplier's profits. Management Science, 32(9), pp. 1177-1185.

Leenders, M., Johnson, P.F., Flynn, A., and Fearon, H. (2006). Purchasing and Supply Management. McGraw-Hill/Irwin, New York, NY.

Mirza, M.A., and Malstrom, E.M. (1994). Required setup reductions in JIT driven MRP systems. Computers and Industrial Engineering, 27(1-4), pp. 221-224.

Monahan, J.P. (1984). A quantity discount pricing model to increase vendor profits. Management Science, 30 (6), pp. 720-726.

Newman, R.G. (1988). The buyer-supplier relationship under justin-time. Production and Inventory Management Journal, 29(3), pp. 45-50.

Pan, A.C., and Liao, C. (1989). An inventory model under just-intime purchasing agreement. Production and Inventory Management Journal, 30(1), pp. 49-52.

Pillac, V., Gendreau, M, Guéret, C., and Medaglia, A.L. (2013). A review of dynamic vehicle routing problems. European Journal of Operational Research, 225 (1), pp. 1-11.

Porras, E., and Dekker, R. (2006). An efficient optimal solution method for the joint replenishment problem with minimum order quantities. European Journal of Operational Research, 174(3), pp. 1595-1615.

Rosenberg, L.J., and Campbell, D.P. (1985). Just in time inventory control: A subset of channel management. Journal of the Academy of Marketing Science, 13(3), pp. 124-133.

Rubin, P.A., and Carter, J.R. (1990). Joint optimality in buyersupplier negotiations. Journal of Purchasing and Materials Management, 26 (2), pp. 20-26.

Sakakibara, S., Flynn, B.B., Schroeder, R.G., and Morris, W.T. (1997). The impact of Just-in-time manufacturing and its infrastructure on manufacturing performance. Management Science, 43(9), pp. 1246-1257.

Schniederjans, M.J., and Cao, Q. (2001). An alternative analysis of inventory costs of JIT and EOQ purchasing. International Journal of Physical Distribution \& Logistics Management, 31(2), pp. 109-123.

Schonberger, R.J., and Ansari, A. (1984). "Just-in-time" purchasing can improve quality. Journal of Purchasing and Materials Management, 20(1), pp. 2-7

Tezuka, K. (2011). Rationale for utilizing 3PL in supply chain management: A shipper's economic perspective. International Association of Traffic and Safety Sciences Research, 35, pp. 24-29.

Thürer, M., Qu, T., Stevenson, M., Maschek, T., and Filho, M.G. (2014). Continuous workload control order release revisited: An assessment by simulation. International Journal of Production Research, 52 (22), pp. 6664-6680.

Weng, Z. K (1995). Channel coordination and quantity discounts. Management Science. 41(9), pp. 1509-1522.

White, R., Pearson, J., and Wilson, J. (1999). JIT manufacturing: A survey of implementations in small and large US manufacturers. Management Science, 45(1), pp. 1-15.

Yang, J., and Pan, J.C. (2004). Just-in-time purchasing: An integrated inventory model involving deterministic variable lead time and quality improvement investment. International Journal of Production Research, 42(5), pp. 853-863.

Yao, Y., Evers, P., and Dresner, M. (2007). Supply chain integration in vendor-managed inventory. Decision Support System, 43(2), pp. 663-774.

Joong Y. Son is Associate Professor of Supply Chain Management in the School of Business at MacEwan University, Edmonton, Canada. He received his Ph.D. in Operations Management from the University of Washington. He also taught at business schools in the US at University of California, Riverside and Kansas State University. His research interests include supply chain coordination and incentive issues, supply chain risk management, production planning and scheduling, and simulation modeling. His research works have appeared in peer-reviewed academic journals and conference proceedings. 